\title{
Industrial pollutants and their effects on the developing babies
}

\begin{abstract}
The human embryo or fetus is relatively more susceptible to the impact of confrontational conditions inside the mother's womb. An industrial pollutant is responsible for more health problems in urban areas in compared to rural areas. The baby at any stages of growth and development have to be compelled to be protected against environmental health hazards. The surroundings environment effects, from early development to growing their health and life which also influences genetically. Today they are at most risk of being exposed to new chemicals that are mostly not tested for fetus and babies. Since the Second World War, approximately 80,000 new artificial chemicals have been factory-made and discharged into the surroundings in massive amounts and estimated about 10 new chemicals being introduced every day. The overwhelming majority of those chemicals haven't been studied adequately for their impacts on human health or fetus. The developmental stage which is understood as the organogenesis period is more vulnerable and prone to any effects of external stimuli. If the any toxic or otherwise any unfavorable effects causes the various adverse effects such as miscarriage, stillbirth, low birth weight, birth defects. Hence, the aims of present work to establishing a causative link between specific environmental exposures pollutants and its outcomes.
\end{abstract}

Keywords: toxicity, pollutants, birth defects and fetus
Volume 4 Issue 6 - 2018

\author{
Vimala Bind,' Akhilesh Kumar² \\ 'Department of Zoology, KN Govt PG College Gyanpur, India \\ ${ }^{2}$ Consultant (Toxicology), India
}

\author{
Correspondence: Akhilesh Kumar, Consultant (Toxicology), \\ Toxicology Division, CIB \& RC, Faridabad, Haryana, \\ India-I2 I00 I, India, Tel +9195 6549 0599; \\ Email akhicibrc@gmail.com
}

Received: October 22, 2018 | Published: November 06, 2018

\section{Introduction}

Pollution is related to negative health outcomes in infants (DeRegenier\& Desai, 2010; Engle, 2010; Evans, 2006; Walker et al., 2011). The small amounts of pollution inflicting the chance to pregnant ladies associated with premature births or with anomalies and conjointly with long-life neurologic and metabolic process disorders in their minors. The larger quantity of maternal exposure of air pollution, a lot of doable to the explanation for the pregnant ladies suffered from intrauterine inflammation that might increase the chance of the variety of health issues for her baby from the embryonic stage to adult. The placenta can be a window into what's occurring in terms of developmental stage exposure and what it suggests that for future health issues. Intrauterine inflammation is one in all the leading causes of premature birth, that happens in one among of every nine births within the USA and one in six African-American births, the researchers say. Babies born prematurely can have lifelong developmental problems. The most of far-famed environmental pollutants are phthalates, bisphenol a plastic product, polychlorinated biphenyls (PCBs). Metals like lead, mercury, metallic element and asbestos, dioxins, polyhalogenated aromatic hydrocarbons (PHAHs), whereas conjointly pesticides, inhaled toxins(tobacco smoke, ozone, particulate matter), and chlorinated medical aid by-products are responsible for this (Table 1). Many of these are cause "endocrine disruptors" suggests that they disrupt the formations, release, transport, binding, and/or breakdown of the maternal hormones which are crucial for the embryonic development and growth at the time of the fetus. Multiple dose (Chronic) exposure may also cause to developmental functional disorders. Several studies have revealed that many such chemical substances (pollutants) may also influence the embryonic development still before conception like lead, dioxin and organochlorine pesticides are lipid soluble and they are maternally accumulation in the body. As a result, there they are liberating of harmful toxic elements throughout gestation and responsible for abnormal fetal development. A number of these toxic chemical pollutants also reached to the offspring through the placenta or during lactation during the fetus developments or after the birth of baby respectively.

\section{Indoor and outdoor air pollution}

Burning of solid fuels for household cooking, heating and lighting may be a major cause of household, or indoor, air pollution. Indoor air pollution puts nearly 3 billion people worldwide at risk of ill health and early death. ${ }^{1}$ In the case of indoor air pollutants which includes the particulate matter (PM10 and PM 2.5), dust mites and bacteria and also includes chemicals and volatile organic compounds (such as formaldehyde and benzene) from paints, personal care products and building materials. ${ }^{2,3} \mathrm{~A}$ global report said that indoor air pollution kills more children than outdoor air pollution, especially in Africa and Asia. Eighteen of the nineteen countries where 95 percent or more of the population use solid fuels for cooking are in sub-Saharan Africa. ${ }^{4}$ However, more than $60 \%$ of the population in the country of India remains to use solid fuels in household cooking purposes which one contributing to over more than 100,000 child deaths associated with indoor air pollution in 2012 as in report. ${ }^{2}$ While the outdoor air pollution tends to be an urban issue, indoor air pollution tends to be more of a rural one. Nevertheless, there is significant overlap and challenges of indoor air pollution in the urban areas, as well as air pollution of outdoor in rural settings. The discrepancy between outdoor and indoor air pollution is more convenient for analytical purposes than it is for practical prevention of exposure in day-today life. During the course of the progress, we passage between indoor and outdoor environments almost seamlessly, and most of the microenvironments between indoor and outdoor are hard to classify. 
Moreover, both indoor and outdoor air conditions are not completely distinct. Burning of biomass fuels for heating, lighting, and cooking, for example, is a major source of ambient, or outdoor, pollution in many cities. ${ }^{5}$

Table I The list of toxic substance, act as a pollutant and their harmful effects

\begin{tabular}{|c|c|c|c|}
\hline S.No. & Toxic substance & Harmful effects & References \\
\hline I & Tobacco smoke & Behavioral, neurological defects, stillbirth, birth defects i.e. cleft palate etc. & Hackshaw et al.., ${ }^{19}$ ATSDR,, 1 \\
\hline 2 & Mercury & Nervous system effects, learning disabilities and limb defects. & Lanphear et al.., ${ }^{20}$ Abelsohn et al. ${ }^{10}$ \\
\hline 3 & Lead & $\begin{array}{l}\text { Miscarriage, low birth weight, neurological delays, anemia, encephalopathy, } \\
\text { paralysis and blindness. }\end{array}$ & Lanphear et al., ${ }^{20}$ ATSDR, ${ }^{\prime \prime}$ \\
\hline 4 & Air pollution & $\begin{array}{l}\text { Preterm birth, growth restriction, heart and lung problems in the infant } \\
\text { and congenital abnormalities. }\end{array}$ & Minguillón et al.., ${ }^{22}$ Backes et al. ${ }^{17}$ \\
\hline 5 & Particulate matter (PM) & $\begin{array}{l}\text { Unhealthy outcomes for fetal development such as poor or slow fetal } \\
\text { growth, and increasing fetal morbidity and mortality. }\end{array}$ & Dejmek et al. ${ }^{18}$ \\
\hline 6 & $\begin{array}{l}\text { Pesticides : Fungicides } \\
\text { diethyltoluamide and vinclozolin }\end{array}$ & Affecting developing fetus. & Wickerham et al. ${ }^{24}$ \\
\hline 7 & Benzenes & Fetal brain defects and neural tube defects. & Webb et al.., ${ }^{23}$ Lupo et al. ${ }^{20}$ \\
\hline 8 & $\begin{array}{l}\text { Toluene and } \\
\text { formaldehyde }\end{array}$ & Causing Miscarriage. & Webb et al..$^{23}$ \\
\hline 9 & Ambient ozone & Affect sperm concentration in men. & Webb et al..$^{23}$ \\
\hline 10 & Carbon dioxide & Decreased oxygen delivery to brain causing intellectual deficiencies. & ATSDR." \\
\hline 11 & lonizing radiation & Miscarriage, low birth weight, physical birth defects, childhood cancers. & ATSDR." \\
\hline 12 & Perchlorate & Risk of low IQ in the Child. & Lazarus. ${ }^{20}$ \\
\hline 13 & Cadmium & $\begin{array}{l}\text { Affect low birth weight, sironemelia (fusion of the lower extremities), } \\
\text { amelia (absence of one or more extremities), delayed ossification of } \\
\text { sternum and costa, facial osseous dysplasia, and behavioral changes. }\end{array}$ & Schoeters et al. ${ }^{15}$ \\
\hline 14 & Polychlorinated biphenyls & $\begin{array}{l}\text { Affecting neurodevelopment, intrauterine growth retardation, brownish } \\
\text { skin pigmentation, liver function abnormality, abnormalities of teeth and } \\
\text { gingival. Later life is also causing low IQ, and behavioral problems. }\end{array}$ & Kadriye. ${ }^{16}$ \\
\hline 15 & Dioxins & Affect the development of the fetus and increase cancer risks later in life. & $\mathrm{Cal} / \mathrm{EPA}$ and ALAC. ${ }^{12}$ \\
\hline 16 & $\begin{array}{l}\text { Polycyclic organic matter } \\
\text { (POM) }\end{array}$ & Affect the development of the fetus and increase cancer risks later in life. & $\mathrm{Cal} / \mathrm{EPA}$ and ALAC. ${ }^{12}$ \\
\hline
\end{tabular}

\section{Methodology}

In this review, we summarised the studies available on the public domains that reported the causal effect of pollutants on the preconception, fetus development and also their effects on the later developments. Subsequently, after the Second World War, more than 80,000 new synthetic chemicals have been manufactured and released into the environment in large amounts, with 10 new chemicals being introduced every day. One-hundred eighty of these 287 chemicals have previously been reported to cause cancer in human and animals, 217 have been associated with birth anomalies, and 217 are neurotoxic. ${ }^{6}$ We also search the data available on 'PubMed' with entitling 'Industrial Pollutants' and 'birth defects' both along with showed 406 numbers of research articles (US National Library of Medicine National Institutes of Health). We collected the information's from these published articles and also collected data and information from the international reputed newspapers also.

\section{Results and discussion}

After the observing the results available in the public domains the epidemiological studies revealed that the person (paternal) working as a fireman, as welder or automobile mechanics have more prone to the spontaneous abortion, congenital abnormalities, and childhood neoplasias. $^{7}$ However, there is no direct relationship established due to conflicting data and more work needed in these directions. Another, the most hazardous substances like the heavy metals such as lead and mercury responsible for spontaneous abortions, while lead caused infertility, stillbirth and spontaneous abortions also when their exposure occurred preconceptionally. ${ }^{8}$ Studies on Mercury showed their effects on nervous system effects, learning disabilities and limb defects. ${ }^{910}$ However, Lead is also responsible for miscarriage, low birth weight, neurological delays, anemia, encephalopathy, paralysis and blindness. ${ }^{9,11}$ So, such studies reported the risk of birth defect (congenital anomalies) increased in offspring whose person (male) worked in an environment where both toxic exposures occur (Table 1). The most known environmental pollutant, 2, 3, 7, 8-tetrachlorodibenzo-p-dioxin causing neural tube defects (NTD) reported (National Academy of Sciences, 2003). ${ }^{12}$ Like this, the study revealed that paternal exposure of pesticides causing acute lymphoblastic leukemia (ALL). ${ }^{13}$ However, the study revealed that the outcome mechanism of congenital anomalies in offspring's due to mutation and epigenetic changes within the sperm if the paternal exposure occurs. Although, from maternal side 'placenta' one of the major way to transfer such toxic chemicals from mother to developing 
a fetus. The non-ionized fat soluble toxic chemicals with low molecular weight $(<1,000$ Daltons) showed evidence of a very rapid placental transfer. This permeability to toxic substances depends on several factors including placental blood flow and metabolism, thickness, the surface area of placenta and transport systems also. After the fifth month of the pregnancy, regular swallowing and breathing movements happen in a fetus with amniotic fluid, so, any toxic material is present in amniotic fluid leading to congenital defects in offspring. Another factor is placental metabolism; it may be harmful to the fetus. When formed metabolites of any non-toxic compound associated with the generation of the products which act as carcinogenic products such as placental enzymes produce some metabolite which associated with DNA and consequence leading developmental defects has been also reported. ${ }^{14}$

Cadmium affects low birth weight, sirenomelia (fusion of the lower extremities), Amelia (absence of one or more extremities), delayed ossification of sternum and costa, facial osseous dysplasia, and behavioral changes. ${ }^{15}$ Polychlorinated biphenyls, also affecting a number of abnormalities such as the neurodevelopment, intrauterine growth retardation, and brownish skin pigmentation, liver function abnormality, abnormalities of teeth while Later life is also causing low IQ, and behavioral problems. ${ }^{16}$ Globally, there are two billion children or $90 \%$ of all children-are exposed to air pollution (WHO). A UNICEF study also published a report that said about 17 million babies suffer air which is six times more toxic than the guidelines. The new research work showed the impact of air pollution on babies in the city like London is significant, but the ratio of effects a relatively very less only about $2.5 \%$ of all full-term newborn with low weight. Conversely, many cities around the world - such as the city like Delhi in India-suffer far higher levels of toxic air, raising concerns of huge impacts on unborn babies in comparison to others. The pregnancy effects of severe exposure environments like Delhi are unmeasured, so, there is an urgent need to turn attention and awareness also for to such environments where large numbers are at considerable risk of harm. UNICEF executive director Anthony Lake said that 'Not only do pollutants harm babies' developing lungs but they can permanently damage their developing brains and, their effects were also seen in futures life. Although, No society can afford to ignore this toxic air pollution to the newborn one. There are several severe public health problems around the world, such as the lack of clean water which responsible for kills of over 500,000 infants every year, but said the toxic air was one of them. (Damian Carrington (Environment editor). Air pollution harm to unborn babies may be global health catastrophe, warn doctors, "The Guardian" international edition, 5 dec 2017). ${ }^{17-24}$

\section{Conclusion}

The hazardous substances which are exposed to the environment as pollutant showed a connection with the adverse fetus development and it's also showing deleterious effect later in life. However, more studies needed to explore to the identified any possible substance that one responsible for the adverse effect on the fetus and take a initiative on the reported regarding the toxic substance or chemicals for their use because of the limited epidemiologic evidence is available regarding the pregnant women. Research revealed that the possible connection between fetal toxic environmental exposures and increase in the congenital abnormalities increasing very fastly in the societies.

\section{Acknowledgments}

Mrs. Vimala Bind contributing in the preparation of the manuscript.

\section{Conflict of interest}

The author declares that there is no conflict of interests regarding the publication of this paper.

\section{References}

1. Dasgupta, Susmita. Who Suffers from Indoor Air Pollution? Evidence from Bangladesh. USA: Oxford University Press; 2006.

2. O’Neill MS, Breton CV, Devlin RB, et al. Air Pollution and Health: Emerging information on susceptible populations. Air Qual Atmos Health. 2012;5(2):189-201.

3. British Columbia Air Quality, 'How Air Quality Affects Health'. 2016.

4. United States Environmental Protection Agency, 'Ozone and Your Patient's Health. 2016.

5. Brandt E, et al. Diesel Exhaust Particle Induction of IL-17A Contributes to Severe Asthma, J Allergy Clin Immunol. 2013;132(5):1194-1204.

6. Crinnion WJ. Maternal levels of xenobiotics that affect fetal development and childhood health. Altern Med Rev. 2009;14(3):212-22.

7. Cordier S. Evidence for a role of paternal exposures in developmental toxicity. Basic Clin Pharmacol Toxicol. 2008;102:176-81.

8. Anttila A, Sallmén M. Effects of parental occupational exposure to lead and other metals on spontaneous abortion. J Occup Environ Med. 1995;37:915-21.

9. Lanphear BP, Vorhees CV, David C. Protecting Children from Environmental Toxins. PLoS Med. 2005;2(3):e61.

10. Abelsohn A, Vanderlinden LD, Scott F, et al. Healthy fish consumption and reduced mercury exposure: counseling women in their reproductive years. Can Fam Physician. 2011;57(1):26-30.

11. ATSDR. Principles of Pediatric Environmental Health: How Can Parents' Preconception Exposures and In Utero Exposures Affect a Developing Child?. Centers for Disease Control and Prevention. 2013.

12. A fact sheet by Cal/EPA (Environmental Protection Agency's) Office of Environmental Health Hazard Assessment and The American Lung Association of California (ALAC). 2003.

13. Torres Sanchez LE, Berkowitz G, et al. Intrauterine lead exposure and preterm birth. Environ Res. 1999;81(4):297-301.

14. Myllynen P, Pasanen M, Pelkonen O. Human placenta: a human organ for developmental toxicology research and biomonitoring. Placenta. 2005;26(5):361-71.

15. Schoeters G, Den Hond E, Zuurbier M, et al. Cadmium and children: exposure and health effects. Acta Paediatr Suppl. 2006;95(453):50-54.

16. KadriyeYurdakök. Environmental pollution and the fetus. Journal of Pediatric and Neonatal Individualized Medicine. 2012;1(1):33-42.

17. Backes $\mathrm{CH}$, Nelin T, Gorr MW, et al. Early life exposure to air pollution: how bad is it?. Toxicology letters. 2013;216(1):47-53.

18. Dejmek J, Selevan SG, Benes I, et al. Fetal Growth and Maternal Exposure to Particulate Matter during Pregnancy. Environ Health Perspect. $1999 ; 107(6): 475$.

19. Hackshaw A, Rodeck C, Boniface S. Maternal smoking in pregnancy and birth defects: a systematic review based on 173687 malformed cases and 11.7 million controls. Hum Reprod Update. 2011;17(5):589-604.

20. Lazarus JH. Controlled Antenatal Thyroid Screening study. Also described in Medscape article: Perchlorate Levels in Pregnancy Linked to Low Childhood IQ, by Nancy A. Melville, 2013. 
21. Lupo PJ, Symanski E, Waller DK, et al. Maternal Exposure to Ambient Levels of Benzene and Neural Tube Defects among Offspring: Texas, 1999-2004. Environ Health Perspect. 2010;119(3):397-402.

22. Minguillón MC, Schembari A, Triguero Mas M, et al. Source apportionment of indoor, outdoor and personal PM2.5 exposure of pregnant women in Barcelona, Spain. Atmospheric Environment. 2012;59:426-36.
23. Webb E, Bushkin Bedient S, Cheng A, et al. Developmental and reproductive effects of chemicals associated with unconventional oil and natural gas operations. Rev Environ Health. 2014;29(4):307-18.

24. Wickerham EL, Lozoff B, Shao J, et al. Reduced birthweight in relation to pesticide mixtures detected in cord blood of full-term infants. Environ Int. 2012;47:80-5. 